Revista de Derecho

\title{
Construcción de espacios transnacionales: el nuevo constitucionalismo latinoamericano
}

Construction of transnational spaces: the new Latin American constitucionalism

\author{
Karla Ayerim Yánez Yánez \\ Docente e investigadora independiente \\ Venezuela \\ kyanez2253@gmail.com \\ ORCID: 0000-0003-0441-9354 \\ Frank Luis Mila Maldonado \\ Coordinador de Investigación de la carrera de Derecho de la Universidad de Otavalo \\ Otavalo, Ecuador \\ fmila@uotavalo.edu.ec \\ ORCID: 0000-0003-4363-5092
}

DOI: https://doi.org/10.32719/26312484.2021.35.8

Fecha de recepción: 25 de marzo de 2020

Fecha de aceptación: 22 de septiembre de 2020

Licencia Creative Commons

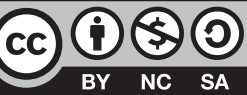




\section{RESUMEN}

El surgimiento del nuevo constitucionalismo latinoamericano ha traído consigo nuevas tendencias que inciden en el derecho constitucional, por ello, surge la siguiente interrogante: ¿el nuevo constitucionalismo latinoamericano promueve la construcción de nuevos espacios transnacionales? Para dar respuesta a ello, se aborda en primer término lo atinente a la evolución del Derecho Constitucional, hasta arribar a las características del denominado nuevo constitucionalismo latinoamericano con la finalidad de obtener el contexto histórico y conocer la génesis de esta tendencia dogmática. Posteriormente, se estudian los aspectos que determinan la creación de los aludidos espacios, tales como la constitucionalización de las diversas ramas del Derecho, el reconocimiento y consagración de sistemas de protección de los Derechos Humanos, la aplicación de la teoría de los Derechos fundamentales, la protección de la naturaleza y el reconocimiento de la interculturalidad, entre otras instituciones transnacionales, que propenden la universalización del Derecho Constitucional. En conclusión, el nuevo constitucionalismo fomenta el antipositivismo, lo que implica la aplicación de principios y procesos hermenéuticos complejos para la aplicación de los derechos fuertemente relacionados con aspectos axiológicos. El trabajo se basa en un estudio dogmáticojurídico, con un enfoque cualitativo, de tipo descriptivo a nivel documental.

PALABRAS CLAVE: constitucionalismo, neoconstitucionalismo, transnacional, latinoamericano, constitucional, derecho.

\section{ABSTRACT}

The emergence of the new Latin American constitutionalism has brought with it new trends that affect constitutional law, therefore, the following question arises: Does the new Latin American constitutionalism promote the construction of new transnational spaces? To respond to this, it is addressed first. what pertains to the evolution of Constitutional Law, until arriving at the characteristics of the so-called new Latin American constitutionalism, this, in order to obtain the historical context and know the genesis of this dogmatic tendency. Subsequently, the aspects that determine the creation of the aforementioned spaces are studied, such as the constitutionalization of the various branches of Law, the recognition and consecration of systems of protection of Human Rights, the application of the theory of fundamental Rights, the protection of nature and the recognition of interculturality, among other transnational institutions, which promote the universalization of Constitutional Law. In conclusion, the new constitutionalism encourages antipositivism, which implies the application of complex hermeneutical principles and processes for the application of rights strongly related to axiological aspects. The work is based on a dogmatic-legal study, with a qualitative, descriptive approach at the documentary level.

KeYwords: Constitutionalism, Neoconstitutionalism, Transnational, Latin American, Constitutional, Law. 


\section{BREVE REFERENCIA A LA EVOLUCIÓN DEL DERECHO CONSTITUCIONAL: APARICIÓN DEL NEO CONSTITUCIONALISMO Y DEL NUEVO CONSTITUCIONALISMO LATINOAMERICANO}

$\mathrm{L}$ os procesos de mundialización, primero, internacionalización, después, y de globalización, actualmente y sobre todo a partir de la caída del Muro de Berlín a finales del siglo XX, han propiciado que los acontecimientos, procesos y acciones significativas que se dan en el mundo no queden circunscritos únicamente al área geográfica en que hayan tenido su origen y viceversa; es decir que los acontecimientos, procesos y acciones a nivel global del sistema internacional han repercutido también en todos los sistemas locales. ${ }^{1}$

Este aspecto ha calado en el plano de Derecho Constitucional, área del Derecho que ha sufrido importantes cambios en las últimas décadas; por ello, indica Carbonell, "el constitucionalismo no ha permanecido como un modelo estático, sino que ha seguido evolucionando en muchos sentidos". ${ }^{2}$ Uno de esos sentidos se basa en la idea de que el instrumento por excelencia que fundamenta el Derecho constitucional es "la Constitución", la cual ha servido de plataforma política para diversos gobernantes de turno, así como de instrumento de contención del poder estatal.

Dicho lo anterior, precisamente existen dos realidades mundiales que han marcado un antes y un después en el ámbito de este campo del Derecho; en primer término, se ubican importantes modificaciones generadas en los últimos cincuenta años, en virtud de la materialización de nuevas constituciones en Europa, principalmente la Constitución de Italia (1947), la Constitución de Alemania (1949), la Constitución de Portugal (1976) y la Constitución de España (1978).

En segundo término, en el ámbito latinoamericano, igualmente se generaron importantes cambios en las últimas décadas, a raíz de las constituciones de Brasil (1988), Costa Rica (1989), México (1992), Colombia (1991), Paraguay (1992), Perú (1993), Argentina (1994), Venezuela (1999), Ecuador (2008) y Bolivia (2009). A pesar de que algunos autores, como Roberto Gargarella, únicamente incluyen a Colombia, Venezuela, Ecuador y Bolivia. ${ }^{3}$ Ciertamente, estos últimos guardan mayores puntos de en-

1. Cuauhtémoc De Dienheim, Constitucionalismo universal: la internacionalización y estandarización de los Derechos Humanos (Buenos Aires: Ad-Hoc, 2009), 82.

2. Miguel Carbonell, "Nuevos tiempos para el constitucionalismo", en Neoconstitucionalismo(s), ed. Miguel Carbonell (Madrid: Trotta, 2003), 9.

3. Roberto Gargarella, "Lo ‘viejo' del 'nuevo' constitucionalismo latinoamericano”, en Memorias Encuentro SELA (Río de Janeiro: Universidad de Yale, 11-14 de junio de 2015), 1. 
cuentros; sin embargo, se destaca el movimiento de materialización de Constituciones en forma relativamente coetánea, lo cual incluso se evidencia en la actualidad con la entrada en vigencia de nuevas Constituciones en la región latinoamericana, con ciertos aspectos que se corresponden con la idea del nuevo constitucionalismo.

Ahora bien, de los impactos generados por la entrada en vigencia de los aludidos instrumentos se ha creado una corriente de la dogmática constitucional que habla de un nuevo constitucionalismo, "neoconstitucionalismo" para el caso de Europa, y de un "nuevo constitucionalismo latinoamericano" para el caso de América Latina.

Ante tal escenario, el neoconstitucionalismo fue utilizado como término, por primera vez, en una comunicación durante el XVIII Congreso Mundial de Filosofía Jurídica y Social celebrado en Buenos Aires en el año de 1997. En aquella ocasión, y posteriormente en el sucesivo libro dedicado al mismo tema, el vocablo fue introducido para indicar una serie de posiciones teóricas - Robert Alexy, Carlos Santiago Nino y Gustavo Zagrebelsky — que estaban delineándose y definiéndose. ${ }^{4} \mathrm{Al}$ respecto, señala Susana Pozzolo que "la palabra neoconstitucionalismo se identifica una perspectiva iusfilosófica que se contraponía explícitamente a aquella iuspositivista y que, al mismo tiempo, trataba de diferenciarse de la opuesta y más tradicional posición iusnaturalista". ${ }^{5}$

Igualmente, es importante advertir que existen algunos autores que critican el alcance del denominado neoconstitucionalismo, al afirmar que ya se ha avanzado el camino hacia sus bodas de oro y no existe claridad respecto del objeto al cual se hace referencia con esta denominación. ${ }^{6}$ Sin embargo, un importante grupo de doctrinarios procura otorgar definiciones acerca del neoconstitucionalismo, ${ }^{7}$ definiéndose como aquel que pretende explicar este conjunto de textos constitucionales que surgen a partir de la década de 1970. Viciano y Martínez aducen que son "constituciones que no se limitan a establecer competencias o separar los poderes públicos, sino que contienen altos niveles de normas materiales o sustantivas que condicionan la actuación del Estado por medio de la ordenación de ciertos fines y objetivos". ${ }^{8}$

4. Susana Pozzolo, “Apuntes sobre neoconstitucionalismo", en Enciclopedia de filosofía y teoría del derecho I, coords. Jorge Fabra y Álvaro Núñez (Ciudad de México: Universidad Nacional Autónoma de México, Instituto de Investigaciones Jurídicas, 2015), 363-4.

5. Ibíd.

6. Eduardo Aldunate, "Aproximación conceptual y crítica al neoconstitucionalismo", Revista de Derecho (Valdivia) 23, n. ${ }^{\circ} 1$ (2010): 79-102.

7. Igual, para algunos autores, este modelo se enfoca más en una teoría del derecho constitucional, basta en la conversión al Estado de Derecho, en Estado Constitucional de Derecho. Vid. Luis Prieto Sanchís, en Carbonell (2003).

8. Roberto Viciano y Rubén Martínez, “Aspectos generales del nuevo constitucionalismo latinoamericano. El nuevo constitucionalismo en América Latina", en Memorias del encuentro internacional. El nuevo 
En tal sentido, tal como indica Comanducci, el neoconstitucionalismo está caracterizado por:

El modelo de sistema jurídico que emerge de la reconstrucción del neoconstitucionalismo está caracterizado, además que por una constitución "invasora", por la positivización de un catálogo de derechos fundamentales, por la omnipresencia en la constitución de principios y reglas, y por algunas peculiaridades de la interpretación y de la aplicación de las normas constitucionales respecto a la interpretación y a la aplicación de la ley. ${ }^{9}$

Por otra parte, encontramos que, entre las características del neoconstitucionalismo, se evidencia que se basa en 1 . El antipositivismo; 2 . Sobre la estructura de las normas jurídicas: los principios; 3. Ponderaciones, balances, desacuerdos. El papel y la racionalidad de los procesos de interpretación/aplicación de los derechos; 4. El derecho y la justicia: la interpretación moral de la Constitución. ${ }^{10}$

Asimismo, otros autores, como Aldunate, sostienen que las características del neoconstitucionalismo, son las siguientes:

a) Constituciones rígidas, con garantía jurisdiccional y alta "densidad" normativa, o alto contenido normativo; b) Constituciones con fuerza normativa vinculante, aplicación directa y constitucionalización del derecho; c) Los derechos fundamentales como valores y el enfoque axiológico del neoconstitucionalismo; d) El método de la ponderación y la superación del positivismo. ${ }^{11}$

Visto lo anterior, se denota la coincidencia entre autores, con lo relativo a la exaltación de los derechos fundamentales, así como de la fuerza normativa de la Constitución y los principios, con lo cual se genera una idea, al menos aproximada, de lo que debe entenderse como neoconstitucionalismo.

Ahora bien, una vez explicado grosso modo el alcance del concepto de neoconstitucionalismo, se realiza una aproximación al denominado nuevo constitucionalismo latinoamericano, concepto que incluso suele ser tratado como sinónimo, por su connotación terminológica, con el significado de "neo", que se traduce en: "nuevo"; sin embargo, las realidades de cada sistema son disímiles, ya que responden a un contexto

constitucionalismo: desafios y retos para el siglo XXI (Quito: Corte Constitucional del Ecuador para el Período de Transición, 2010), 17.

9. Paolo Comanducci, "Formas de (neo)constitucionalismo: un análisis metateórico", trad. Miguel Carbonell, Revista Isonomía, n. ${ }^{\circ} 16$ (2002): 97.

10. Pozzolo, "Apuntes sobre neoconstitucionalismo", 363-4.

11. Aldunate, "Aproximación conceptual y crítica al neoconstitucionalismo", 79-102. 
y a una realidad diferentes, a pesar de coincidir en diversos aspectos, tales como el reconocimiento de los derechos fundamentales.

Dicho lo indicado, según Pedro Salazar, el nuevo constitucionalismo latinoamericano "es la denominación con la que han sido bautizados los procesos constituyentes y el resultado de los mismos de algunos países de América Latina en los últimos años del siglo XX y la primera década del XXI". ${ }^{12}$

Por su parte, sostiene Rodrigo Uprimny que las características medulares de estos procesos constitucionales:

Son relativamente recientes, se basa en que confieren a los ordenamientos actuales cierto aire de familia. Es posible entonces hablar de un constitucionalismo latinoamericano actual que tiene rasgos distintivos frente a otros constitucionalismos del mundo contemporáneo o frente a los ordenamientos de la región en el pasado. ${ }^{13}$

Sin embargo, el mero hecho de que se genere un fenómeno en la región de materializar reformas sustanciales o la entrada en vigencia de Constituciones no constituye per se un nuevo constitucionalismo. Esta idea, a pesar de ser reconocida por un importante sector de la doctrina, también encuentra detractores, ya que cada país posee una realidad o contexto particular al cual debe responder su sistema u ordenamiento jurídico. Sin embargo, se trata de ciertos aspectos comunes que apuntan a una idea trasnacional de derecho. Al respecto opina Gargarella que, en su examen de las diferentes constituciones de la región, asumirá siempre que ellas — más allá de las obvias complejidades que les son propias-, se encuentran unidas por ciertos rasgos comunes. Ante todo, considera que todas ellas aparecen divididas en dos partes principales, esto es, la sección orgánica, referida a la organización del poder, y la sección dogmática, referida a la declaración de derechos. La primera de tales partes define los rasgos principales de lo que podríamos llamar la "maquinaria democrática" (ella establece, por ejemplo, los modos en que van a funcionar y relacionarse las distintas ramas del Poder, típicamente, el Poder Ejecutivo, el Legislativo y el Judicial). La segunda parte, mientras tanto, determina cuáles son los derechos fundamentales que cada una de las comunidades involucradas que reconoce como tales. ${ }^{14}$

12. Pedro Salazar, "El nuevo constitucionalismo latinoamericano (una perspectiva crítica)", en El constitucionalismo contemporáneo. Homenaje a Jorge Carpizo, coords. Luis González y Diego Valadés (Ciudad de México: UNAM, 2013), 348.

13. Rodrigo Uprimny, "Las transformaciones constitucionales recientes en América Latina: tendencias y desafíos", en El derecho en América Latina: un mapa para el pensamiento jurídico en el siglo XXI, coord. César Rodríguez (Buenos Aires: Siglo XXI, 2011), 126.

14. Roberto Gargarella, "Sobre el nuevo constitucionalismo latinoamericano". Revista Uruguaya de Ciencia. Política 27, n. 1 (2018): 110. 
Sostenidas las anteriores generalidades, es preciso ahondar en lo atinente al nuevo constitucionalismo latinoamericano, el cual es uno de los aspectos medulares de esta investigación para la construcción de espacios transnacionales.

\section{EL NUEVO CONSTITUCIONALISMO LATINOAMERICANO}

En relación al nuevo constitucionalismo latinoamericano, aduce Gargarella, que la evolución del constitucionalismo regional podría ser dividida en cuatro etapas, dirigidas:

i) el constitucionalismo "experimental", particularmente preocupado por la consolidación de la independencia (1810-1850); ii) el "fundacional", interesado, sobre todo, en la consolidación económica (1850-1917); iii) el "social", orientado a recuperar la olvidada "cuestión social" (1917-1980); y iv) el de los derechos humanos, dirigido a sanear la crisis de derechos humanos propia de la década del 1970 (1980-2000). ${ }^{15}$

Por otra parte, entre las características del nuevo constitucionalismo latinoamericano, los autores Viciano y Martínez ${ }^{16}$ escinden entre dos grandes bloques y ubican las formales, como rasgos distintivos del nuevo constitucionalismo, y materiales, como fundamentos del nuevo constitucionalismo, resumidas ambas, al siguiente tenor:

Formales: 1. La legitimidad (procesos democráticos); 2. Necesidad de cambios (ruptura de la continuidad constitucional); 3. Innovación (originalidad) ${ }^{17} 4$. Extensión (amplitud); 5. Capacidad de conjugar elementos técnicamente complejos con un lenguaje asequible (complejidad) ${ }^{18} 6$. Activación del poder constituyente ante cualquier cambio (rigidez). (Martínez Dalmau); 7. Se fundamentan en principios, implícitos y explícitos, en detrimento de las reglas, que son más limitadas (su uso en la interpretación). ${ }^{19}$

Lo anterior debe tener un tratamiento cauteloso, puesto que pudiese rebasar fronteras, trastocando principios medulares del Estado de Derecho, convirtiéndose en un populismo constitucional, ya que se pretende ofrecer cambios que solo quedan en papel, utilizando un lenguaje de escasez técnica que se basa en premisas poco reales y que parten de la búsqueda demagógica disfrazada de procesos democráticos que, en el

15. Ibíd.

16. Viciano y Martínez, “Aspectos generales del nuevo constitucionalismo latinoamericano. El nuevo constitucionalismo en América Latina", 17.

17. Roberto Gargarella y Christian Courtis, "El nuevo constitucionalismo latinoamericano: promesas e interrogantes", Serie Políticas Sociales 153 (Santiago: Cepal, 2009): 1-45.

18. Realidad de cada contexto. Pluralismo, etc.

19. Viciano y Martínez, “Aspectos generales del nuevo constitucionalismo latinoamericano. El nuevo constitucionalismo en América Latina", 26-33. 
fondo, solo intentan la concentración del poder y además en la falta de instrumentos que permitan materializar los principios consagrados en el texto constitucional. Algunos autores señalan tales aspectos como la mayor debilidad de la teoría in commento. Ahora bien, en relación a las características materiales, se señalan las siguientes:

Materiales: 1. Búsqueda de recomponer la pérdida de relación entre soberanía popular y gobierno. Democracias participativas; 2. Profusa carta de derechos de las nuevas Constituciones e incluso identificación de grupos débiles: a) Recepción de convenios internacionales de derechos humanos; b) Búsqueda de criterios de interpretación más favorables para las personas; c) Acciones directas de amparo (protección), derechos sociales, reconocidos, máxima efectividad; 3. Plantean la integración de sectores históricamente marginados (indígenas); 4. Normatividad de la Constitución, carácter normativo y superior frente al resto del ordenamiento jurídico. Medidas de acción directa de la Constitución, tutela o amparo, se añade la normatividad, control concentrado (elementos directamente implicados en la democracia). Paso de un sistema de control difuso débil a la creación de fórmulas concentradas o mixtas. Interpretación constitucional; 5. Desigualdades económicas, se busca superar con las Constituciones económicas. Modelos económicos, desde iniciativa privada, justicia redistributiva, hasta la protección de la economía comunitaria. Integración económica. ${ }^{20}$

La anterior categoría merece una observación similar a la planteada a los aspectos formales, ya que se busca ganar popularidad, identificando grupos débiles, realizando promesas de reivindicación de dichos sectores a través de aspectos económicos y sociales. Sin embargo, se resalta que dichos aspectos deben ser tratados de forma cuidadosa y con conocimientos profundos de los ejes fundamentales que circundan un Estado de Derecho, puesto que, de otra manera, se desvirtuaría la esencia del nuevo constitucionalismo.

Igualmente, a pesar de que se hace alusión a la rigidez para realizar cualquier cambio a la Constitución, se han evidenciado algunos escenarios en los cuales se ha soslayado esa pretensión. Asimismo es preciso advertir que ciertamente se propugna con el nuevo constitucionalismo el reconocimiento de principios sobre apartados normativos, lo cual es aceptable, sin embargo, su tratamiento debe realizarse con la mayor coherencia en virtud que no se puede hacer valer cualquier interpretación en nombre de los principios con intereses acomodaticios, sino conforme a ciertos métodos de hermenéutica, argumentación jurídica y sobre la base de la teoría de los derechos fundamentales.

20. Ibíd., 34-7. 
Similar a lo señalado anteriormente, a pesar de que los autores citados no lo indican de manera directa, ergo, se deducen de la búsqueda de superación de desigualdades sociales, lo cual implica el reconocimiento de los derechos sociales que, incluso, se predica su máxima observancia al hablar de un Estado social de Derecho y de Justicia. Ello implica que deba reflexionarse sobre las posiciones excluyentes entre sí, de Derecho y de Justicia, en virtud de que, cuando se habla de Justicia, es un concepto abstracto más amplio que permite hacer interpretaciones tan amplias que sobrepasan el ámbito del derecho, es decir, se puede dejar de reconocer derechos individuales en nombre de la justicia.

Por último, los sistemas de control constitucional, concentrado o mixtos, representan algunos problemas a nivel de Tribunales o Cortes Constitucionales, para lo cual vale la misma observación que se ha sostenido, que radica en que debe existir un equilibrio entre poderes, en aras de que no existan excesos a nivel de la denominada actividad paralegislativa o actividad del juez como legislador positivo, que ha sido reflejo de algunos países en los cuales se ha pervertido la función judicial a nivel constitucional, en casos que incluso se ha reflejado el mantenimiento en el poder de un gobierno, gracias a salas constitucionales, a través de decisiones de carácter vinculante.

Ahora bien, ciertamente no existen contornos matemáticos relativos al contenido o alcance del nuevo constitucionalismo latinoamericano, sin embargo, existen elementos comunes en las Constituciones de la región, los cuales son recogidos a continuación, basándonos en los aspectos que propugnan la construcción de espacios transnacionales, tal como se analiza a continuación.

\section{CONSTRUCCIÓN DE ESPACIOS TRANSNACIONALES A TRAVÉS DEL NUEVO CONSTITUCIONALISMO. HACIA LA UNIVERSALIZACIÓN DEL DERECHO CONSTITUCIONAL}

En relación a la construcción de espacios transnacionales, José Aranda, indica que:

Los espacios transnacionales que ya no se ubican en un ámbito territorial específico y acotado por las fronteras nacionales hasta llegar al nivel local, sino toda una "nueva" y diversa configuración espacial con al menos dos sitios de referencia entre los que se establece un variado conjunto de interrelaciones, intercambios e interacciones entre los orígenes y los destinos, y donde las mismas personas inmigrantes ocupan simultáneamente ambas posiciones, desempeñando asimismo distintos roles y paralelamente sus respectivas actividades. $^{21}$

21. José Aranda, "Espacios transnacionales y derechos humanos de las migrantes y los migrantes", en $M i$ - 
Lo anterior se traduce en la necesidad de que las "políticas nacionales tendrían que percatarse de los espacios transnacionales", ${ }^{22}$ al momento de proyectarse acciones, aspecto que abarca el plano del Derecho Constitucional, como área medular del Derecho, la cual actualmente reclama cada vez más la observación de los espacios transnacionales, reflejados con los siguientes fenómenos.

\section{EL FENÓMENO DE LA CONSTITUCIONALIZACIÓN DE LAS DISTINTAS ÁREAS DEL DERECHO}

Según Castañeda, en su forma más elemental, "la constitucionalización del derecho hace alusión al fenómeno según el cual el ordenamiento jurídico de un país y por tanto el derecho en sí mismo considerado, debe estar regido en su interpretación y aplicación por la Constitución de dicho país". ${ }^{23}$

En razón del continuo avance del derecho constitucional, las premisas del sistema clásico legalista han evolucionado en diversos sentidos:

(i) en cuanto al papel de la norma, se verificó que los problemas jurídicos no siempre están en el relato abstracto del texto normativo. Muchas veces, solo es posible producir la respuesta constitucionalmente adecuada a la luz del problema, de los hechos relevantes, analizados de manera tópica; (ii) en cuanto al papel del juez, ya no le corresponderá solamente una función vinculada al conocimiento técnico, relegado al simple acto de revelar el contenido de la norma. El intérprete deberá tener una participación decisiva en el proceso de creación del Derecho, con un sentido de complementariedad al trabajo del legislador, en especial cuando realiza la tarea de valorar el sentido de las cláusulas abiertas y de realizar elecciones entre las soluciones posibles. ${ }^{24}$

Lo expuesto ha generado que en la actualidad el acto de interpretar las normas jurídicas y dar solución a los conflictos de intereses no se limiten a la subsunción clásica, es decir, el acto a través del cual se ajustaban los hechos al derecho, o a los tradicio-

gración, democracia y desarrollo: la experiencia mexiquense, coords. Norma Baca, Francisco Herrera y Rocío González (Ciudad de México: Instituto Electoral del Estado de México, 2009), 21-2.

22. Mauricio Salazar, "Espacios transnacionales. Migración y globalización. Teoría de la Educación”, Revista electrónica teoría de la educación. Educación y cultura en la sociedad de la información (Universidad de Salamanca) 9, n. 2 (2008): 165.

23. Paula Castañeda, "La constitucionalización del derecho en la sociedad capitalista", Derecho y realidad: Revista de la Facultad de Derecho y Ciencias Sociales UPTC 8, n. ${ }^{\circ} 16$ (2010): 71.

24. Luis Barroso, "El neoconstitucionalismo y la constitucionalización del derecho en Brasil (El triunfo tardío del derecho constitucional en Brasil)". Revista de Derecho de la Universidad de Montevideo, año 6, n. ${ }^{\circ} 12$ (2007): 30 . 
nales métodos de resolución de conflictos normativos - lex superior; lex especialis, lex posterior-, sino que, por el contrario, se utilicen otras herramientas derivadas de la hermenéutica constitucional como la interpretación conforme, los principios, la ponderación, la proporcionalidad y en general la argumentación para dar respuesta a los casos difíciles, en los cuales pueden coexistir diversas soluciones válidas.

Apunta Barroso que "la idea de constitucionalización del Derecho aquí explorada está conectada con el efecto expansivo de las normas constitucionales, cuyo contenido material y axiológico se irradia, con fuerza normativa, por todo el sistema jurídico". ${ }^{25}$ Esto supone un reto en determinadas áreas del derecho que a través de la historia se han basado en los métodos de interpretación clásica y restrictiva como por ejemplo el derecho penal.

En el caso ecuatoriano, con la Constitución de 2008, "la Constitución empezó a disfrutar no solamente de una supremacía en sentido formal, sino de una supremacía material, axiológica, potenciada por la apertura del sistema jurídico y por la normatividad de sus principios. Con gran ímpetu, exhibiendo su fuerza normativa sin precedentes", ${ }^{26}$ siendo que la Constitución no solo ingresó al ordenamiento jurídico sino en la argumentación de todos los que componen el sistema. Al punto que la Constitución ecuatoriana en su art. 11 núm. 4 señala que ninguna norma puede restringir el contenido de los derechos y garantías constitucionales.

Un ejemplo claro se ubica en el ámbito del Derecho Penal, por ello, apunta Luigi Ferrajoli, que "Es claro que el derecho penal mínimo, es decir, condicionado y limitado al máximo, corresponde no solo al máximo grado de tutela de las libertades de los ciudadanos respecto del arbitrio punitivo, sino también a un ideal de racionalidad y de certeza". ${ }^{27}$

Asimismo, el Código Orgánico Integral Penal (2014) en su exposición de motivos dedica un número a esta temática, haciendo referencia a la doble función del derecho penal frente a los derechos de las personas. Por un lado, protege derechos y, por otro, los restringe. Desde la perspectiva de las víctimas, los protege cuando alguno ha sido gravemente lesionado. Desde la persona que se encuentra en conflicto con la ley penal, puede restringir excepcionalmente sus derechos, cuando una persona vulnera los derechos de otras y justifica la aplicación de una sanción. ${ }^{28}$ Como corolario, el mismo Código consagra que la interpretación de los tipos penales debe realizarse conforme a la Constitución.

25. Ibíd., 37.

26. Ibíd.

27. Luigi Ferrajoli, Derecho y razón, teoría del garantismo penal, 10. ${ }^{a}$ ed. (Madrid: Trotta, 2011), 104.

28. Código Orgánico Integral Penal (2014). Exposición de motivos. 
En tal sentido, los principios medulares del Derecho penal en su parte general encuentran cobijo en la Constitución (legalidad, culpabilidad, penas humanas, mínima intervención, entre otros), partiendo de la idea de que un modelo de Estado define el camino o la visión del derecho penal, por ello, un Estado Constitucional de Derechos posee diversas características que inciden plenamente en el ámbito del Derecho penal.

Otro ejemplo claro de la constitucionalización del Derecho penal se evidencia en el artículo 76 de la Constitución, ${ }^{29}$ que ordena que las penas estén acordes con el principio de proporcionalidad, es decir, debe existir cierta relación coherente entre el grado de vulneración de un derecho y la gravedad de la pena. Y, por otra parte en el artículo 78 , incorpora la figura de la reparación integral, dando un sentido más amplio que el puramente punitivo. En consecuencia, tal como lo expresa el COIP, es indispensable determinar la correspondencia constitucional de los bienes jurídicos protegidos y las garantías de quienes se someten a un proceso penal en calidad de víctimas o procesados para que estén adecuadamente regulados y protegidos.

Otra expresión del nuevo constitucionalismo latinoamericano radica en el Derecho Ambiental y su constitucionalización. En Latinoamérica países como Bolivia, Chile, Perú, Venezuela y el Ecuador han incluido en sus constituciones de forma innovadora y relevante al derecho ambiental. Al respecto señalan Mila y Yánez ${ }^{30}$ que se ha podido evidenciar:

la inclusión de principios y reglas que regulen la protección, el cuidado y las formas de relación del hombre con el ambiente y la naturaleza, a tal punto, de reconocerse el derecho a un ambiente sano, ecológicamente equilibrado, libre de contaminación, como derechos fundamentales de las personas, y, en el caso de la constitución ecuatoriana, generar un nuevo paradigma en tanto la misma considera a la naturaleza como sujeto de derechos, es decir, dota de personalidad jurídica a la naturaleza en la búsqueda de garantizar el buen vivir y la sostenibilidad para las generaciones futuras.

Asimismo, existe la denominada responsabilidad integral en casos de daños ambientales, lo cual denota un nuevo paradigma de protección ambiental.

29. Constitución de la República del Ecuador (2008).

30. Frank Mila y Karla Yánez, "El constitucionalismo ambiental en Ecuador", Actualidad jurídica ambiental, n. ${ }^{\circ} 97$ (enero 2020): 11. 


\section{RECONOCIMIENTO DE LA CIUDADANÍA UNIVERSAL (MOVILIDAD HUMANA)}

Por otra parte, existen otros fenómenos como el de la Movilidad Humana, elemento que de igual manera forma parte de la constitucionalización, puesto que, desde la filosofía constitucional, tal como lo señala Alexy:

la validez del derecho implica, en primer lugar, una validez jurídica que supone que la norma es dictada por órgano competente y según un procedimiento previsto; en segundo lugar, una validez moral, que supone que la norma está moralmente justificada y el sistema posee una pretensión de corrección en caso de normas injustas, y, en tercer lugar, una validez social, que supone que la norma vale socialmente porque es obedecida, y en caso de desobediencia se aplica una sanción. ${ }^{31}$

En un sentido favorecedor a la movilidad, y en respuesta a los efectos de exclusión propios de la ciudadanía, se encuentran los derechos humanos, los cuales contribuyen en pro del reconocimiento de una ciudadanía universal, dando solución a estos conflictos provenientes de la globalización. Algunos autores sostienen que la globalización genera fenómenos sociales que superan el alcance estatal, lo cual a su vez propicia vulneraciones a los derechos humanos a aquellas personas - ciudadanosmigrantes, marginadas y discriminadas, que pueden reclamarse en diversos niveles (nacional e internacional), lo que se traduce en un "hueco de ciudadanía". ${ }^{32}$ Es decir, personas que no pertenecen ni a un lugar ni a otro, bien porque migraron o porque, dentro del Estado del cual son ciudadanos, se les considera de segunda clase. Lo anterior en razón de que los derechos humanos constituyen un orden supranacional, aunado al andamiaje jurisdiccional que tiene fuerza coercitiva frente a los Estados.

Luigi Ferrajoli en su teoría de la postciudadania y ciudadanía universal concluye que los derechos - peregrinandi, migrandi, degendi- fueron proclamados como iguales y universales: el derecho de residencia, movilidad y libre circulación. ${ }^{33}$ En ese sentido, señala Estévez ${ }^{34}$ que la ciudadanía universal va de la mano del reconocimien-

31. Robert Alexy, "La validez del derecho", en Concepto y validez del derecho (Barcelona: Gedisa, 1994), $87-122$.

32. Alison Brysk y Gershon Shafir, People Out of Place: Globalization, Human Rights, and the Citizenship Gap (Nueva York: Routledge, 2004), citado en Ariadna Estévez, “¿Derechos humanos o ciudadanía universal? Aproximación al debate de derechos en la migración”. Revista Mexicana de Sociología 78, n. ${ }^{\circ} 1$ (2016): 70 .

33. Luigi Ferrajoli, Derechos y garantías: la ley del más débil (Madrid: Trotta, 1999), 98.

34. Estévez, “¿Derechos humanos o ciudadanía universal? Aproximación al debate de derechos en la migración”, 61 . 
to de derechos humanos universales a todas las personas, independientemente de su ciudadanía nacional.

Es por ello que se coincide en lo expuesto por Ferrajoli cuando afirma que:

Tomar en serio estos derechos significa hoy tener el valor de desvincularlos de la ciudadanía como pertenencia (a una comunidad estatal determinada) y de su carácter estatal. Y desvincularlos de la ciudadanía significa reconocer el carácter supraestatal en los dos sentidos de su doble garantía constitucional e internacional-y por tanto tutelarlos no solo dentro sino también fuera y frente a los Estados, poniendo fin a este gran apartheid que excluye de su disfrute a la mayoría del género humano contradiciendo su proclamado universalismo. ${ }^{35}$

Esta teoría procura romper el esquema clásico del constitucionalismo, resaltando la dimensión deontológica de los derechos humanos y propendiendo la generación de espacios transnacionales, resaltando la dignidad humana, sobre las concepciones de soberanía y ciudadanía.

En ese sentido, autores como Martin Yuste aducen que las naciones no necesitan para existir reclamar un territorio exclusivo y excluyente, y que además no deben ser cárceles, ${ }^{36}$ por el contrario, cualquier Estado que se precie de constitucional no deberá prohibir la libre circulación, puesto que, en caso de hacerlo tal como señala el autor, demostrará su verdadero carácter, alejado de un interés genuino en el cumplimiento y protección de los derechos humanos.

Por ello se considera que, más allá de los conceptos clásicos de soberanía, se superponen los derechos constitucionales y humanos de las personas, y que, en ese sentido, la circulación de las personas ente un Estado y otro debería ser irrelevante, en cuanto a la condición de extranjero, existiendo incluso algunos Estados que en sus Constituciones, como es el caso del Ecuador, propugnan el principio de ciudadanía universal, la libre movilidad de todos los habitantes del planeta y el progresivo fin de la condición de extranjero como elemento transformador de las relaciones desiguales entre los países. ${ }^{37}$

Por último, dada la diversidad cultural en las sociedades contemporáneas propia de la movilidad humana, debemos decantarnos por una ciudadanía que sirva de vínculo de unión entre grupos sociales diversos, es decir, una ciudadanía compleja y pluralista, capaz de tolerar, respetar e integrar las diversas culturas. ${ }^{38}$ Sin embargo, en la actualidad, a pesar de que la mayoría de los Estados latinoamericanos se tildan de

35. Ferrajoli, Derechos y garantías, 97.

36. Juan Martín, Estado universal. Ni muros, ni fronteras (Bubok Publishing S.L., 2018), 107.

37. Constitución de la República del Ecuador (2008), art. 416.

38. Virginia Guichot, Reconstruir la ciudadanía (Madrid: Dykinson, 2013). 
Derecho, de Derechos, Social o Constitucional, hacer una declaración de ese tipo no implica que la apariencia sea la realidad. Un ejemplo sencillo de esto lo notamos en el fenómeno de la criminalización de los migrantes, aspecto que en materia penal se encuentra desechado por teorías modernas como el principio del acto y se evidencia a través de políticas de "securitización" de algunos Estados, que en el fondo solo discriminan e identifican como enemigos a los extranjeros.

\section{DERECHO INTERNACIONAL DE LOS DERECHOS HUMANOS, SISTEMAS DE PROTECCIÓN Y CONTROL DE CONVENCIONALIDAD}

El Derecho Internacional juega un papel fundamental dentro del nuevo constitucionalismo latinoamericano, puesto que - refiriéndonos especialmente al derecho internacional de los derechos humanos-, de las obligaciones estatales derivadas de la suscripción de convenios y tratados internacionales, se incluye el deber de los Estados de generar normativa armonizada en estos contextos de derechos humanos.

En ese sentido, el sistema de protección interamericano tiene un objetivo igual al sistema europeo, pero con América, inscrito en el marco de la OEA, contando con órganos especializados en la protección de los derechos humanos, tales como la Comisión y la Corte Interamericana de Derechos Humanos. Este sistema, y especialmente la Corte Interamericana de Derechos Humanos a través de su jurisprudencia, ha venido construyendo una figura denominada control de convencionalidad, la cual tiene como finalidad la armonización del derecho interno de casa país o Estado Parte de la Convención Americana de Derechos Humanos (1969) con lo establecido en la referida convención.

El control de convencionalidad ha sido definido por la Corte Interamericana de Derechos Humanos como una institución que se utiliza para aplicar el Derecho Internacional, en este caso el Derecho Internacional de los Derechos Humanos, y específicamente la Convención y sus fuentes, incluyendo la jurisprudencia de la Corte IDH, en el Derecho interno de los Estados parte de aquella. ${ }^{39}$ Esta figura supone un aporte sustancial para la construcción de espacios trasnacionales, puesto que, tal como apunta Fernández, ${ }^{40}$ todos los actos y actividades del Estado parte están sometidos a este

39. Corte Interamericana de Derechos Humanos, Caso Gelman vs. Uruguay. Supervisión de cumplimiento de sentencia de 20 de marzo de 2013.

40. Francisco Fernández, "Carlos Ayala Corao: Del diálogo jurisprudencial al control de convencionalidad", Anuario Iberoamericano de Justicia Constitucional, n. 17 (2013): 675; Mario Midón, Control de convencionalidad (Buenos Aires: Astrea, 2016), 76. 
control, comenzando por la propia Constitución y las leyes, los actos administrativos, las sentencias y, en general, todos los demás actos estatales.

La Corte Interamericana ha establecido que la obligación de aplicar este control de convencionalidad no solamente le corresponde a la Corte como órgano especializado, sino que ha ampliado dicha obligación a cada uno de los Estados parte, y, en consecuencia, a cada poder y a cada nivel estatal; en ese sentido, tenemos un control concentrado de convencionalidad que "se trata de la competencia asignada a un tribunal internacional para determinar la responsabilidad internacional de los Estados partes cuando vulneran el derecho convencional a través de sus normas o actos". ${ }^{41} \mathrm{Y}$, por su parte, el control difuso de convencionalidad "es el que se ejerce por los Estados. Es el juez del Estado el que se encuentra obligado a ejercer este control, interpretando las normas internas conforme la Convención Americana y verificando su adecuación a esta última". ${ }^{42}$

En consecuencia, estas instituciones, a través del ejercicio de sus competencias y de figuras como el control de convencionalidad, hablan de uniformidad y universalización en la temática relativa a la protección de los Derechos humanos, lo cual se traduce en un espacio ventana para un alcance transnacional del Derecho Constitucional.

Sin embargo, esta teoría resulta en algunos casos ineficaz, puesto que, tal como aducen los detractores del control de convencionalidad, por ejemplo, Castilla ${ }^{43}$, tiene algunas debilidades en el ejercicio práctico, siendo la más relevante de ellas el sustento jurídico para su aplicación, en virtud de que se considera que dependerá del rango jerárquico que se les otorgue a los instrumentos de derechos humanos dentro del ordenamiento jurídico de cada Estado.

\section{RECONOCIMIENTO Y APLICACIÓN DE LA TEORÍA DE LOS DERECHOS FUNDAMENTALES}

De la mano con el sistema de protección de Derechos Humanos, el reconocimiento y aplicación de la teoría de los Derechos Fundamentales sirve de plataforma para dar un mejor tratamiento a lo relativo a los derechos humanos, es decir, esos derechos humanos constitucionalizados que se conocen como derechos fundamentales cuentan

41. Betiana Neubaum, "El diálogo interjurisdiccional entre la Corte Interamericana y la Corte Suprema de la Nación Argentina. El control de convencionalidad y la interpretación conforme", Revista Electrónica Cátedra Jean Monnet (Universidad de Buenos Aires, Facultad de Derecho) 4, n. 2 (2016): 59.

42. Ibíd., 60 .

43. Karlos Castilla, "Control de convencionalidad interamericano: una propuesta de orden ante diez años de incertidumbre", Revista IIDH (2016): 88. 
con una teoría que permite tratar la restricción de los mismos, respetando su núcleo duro o contenido esencial.

En ese sentido, las normas relativas a la dignidad de la persona humana y sus derechos se encuentran en la cúspide de la estructura normativa - sea esta estatal o internacional - debiendo subordinársele todas las otras normas; ${ }^{44}$ por ello, en la actualidad, existe un orden jurídico plural, es decir, un orden legal nacional, que se complementa con otras supranacionales y globales, ${ }^{45}$ es decir, que todas las normas no son monopolizadas por el Estado.

Para Aguilera, "los derechos fundamentales constituyen, de este modo, la categoría jurídica que engloba a los derechos humanos universales y los derechos ciudadanos nacionales. Ambas clases de derechos fundamentales son, parte integrante, necesaria e ineludible de la cultura jurídica de todo Estado constitucional". ${ }^{46}$ A pesar de ello, la soberanía y la ciudadanía en la actualidad continúan generando conflictos relacionados con la exclusión entre los Estados y las personas; para ello, esta teoría, aunada a métodos hermenéuticos como la ponderación y la proporcionalidad para solventar dichos conflictos de intereses, en ese sentido, la aplicación de esta teoría permite hablar de construcción de un enfoque transnacional de los derechos fundamentales como elementos sustanciales del nuevo constitucionalismo latinoamericano.

La distinción entre derechos fundamentales y derechos humanos no debe llevarnos a pensar que se trata de categorías separadas e incomunicadas. Por el contrario. De hecho, podríamos decir que todos los derechos fundamentales son derechos humanos constitucionalizados. ${ }^{47}$

Lo anterior es ratificado por Alexy cuando señala que todo derecho fundamental está recogido en una "disposición de derecho fundamental"; una disposición de ese tipo es un enunciado previsto en la Constitución o en los tratados internacionales que tipifican un derecho fundamental. ${ }^{48}$

En ese sentido, es una realidad, al menos en Latinoamérica, que la mayoría de los Estados en las últimas décadas han incorporado a sus ordenamientos jurídicos y especialmente a sus constituciones aspectos relativos a los derechos humanos, con lo

44. Gonzalo Aguilar, "Derechos fundamentales-derechos humanos. ¿Una distinción válida en el siglo XXI?”, Boletín Mexicano de Derecho Comparado, nueva serie, año XLIII, n. ${ }^{\circ} 127$ (2010): 16.

45. Michel Rosenfeld, "Rethinking constitutional ordering in an era of legal and ideological pluralism", International Journal of Constitutional Law 6, n. ${ }^{\circ}$ 3-4 (2008): 415.

46. Rafael Aguilera, "La ciudadanía ante la globalización: nuevos modelos de la ciudadanía posnacional y transcultural", Revista de Derecho UNED, n. ${ }^{\circ} 8$ (2011): 30.

47. Miguel Carbonell, Los derechos fundamentales en México (Ciudad de México: Universidad Nacional Autónoma de México / Comisión Nacional de los Derechos Humanos, 2004), 9.

48. Robert Alexy, Teoría de los derechos fundamentales, trad. Ernesto Garzón Valdés (Madrid, 2002), 63. 
cual, de cierto modo existe una tendencia a promover y garantizar la protección de estos derechos, otorgándoles fuerza de fundamentales dentro de sus sistemas jurídicos. Sin embargo, se debe resaltar que esta teoría aún se encuentra en construcción y se corresponde con aspectos abstractos, no obstante, corresponde a los tribunales y a la dogmática constitucional desarrollar estos postulados de una forma más específica.

\section{REALIDAD PLURINACIONAL (INTERCULTURALIDAD)}

Por último, existe una realidad de ciertos países latinoamericanos, como Ecuador, Bolivia, Venezuela, Perú, entre otros, que reconoce expresamente la tendencia de reconocer la plurinacionalidad o interculturalidad de los Estados, permitiendo la coexistencia de diversos sistemas jurídicos.

Al respecto, Grijalva opina que:

Para el constitucionalismo latinoamericano la diversidad cultural implica un desafío aún mayor y de connotaciones propias. Bajo la presión de los movimientos indígenas y en un esfuerzo de legitimación que problematiza su indudable impronta neocolonial, varios Estados latinoamericanos han constitucionalizado, bajo fórmulas variables, el derecho a la diversidad cultural y a la identidad. Tal reconocimiento ha incluido expresiones culturales claves de los pueblos indígenas, por ejemplo, sus idiomas, territorios y sistemas de autoridad y normativos. ${ }^{49}$

En el mismo orden de ideas, Ramiro Ávila aduce que:

El constitucionalismo plurinacional es o debe ser un nuevo tipo de constitucionalismo basado en relaciones interculturales igualitarias que redefinan y reinterpreten los derechos constitucionales y reestructuren la institucionalidad proveniente del Estado Nacional. El Estado plurinacional no es o no debe reducirse a una Constitución que incluye un reconocimiento puramente culturalista, a veces solo formal, por parte de un Estado en realidad instrumentalizado para el dominio de pueblos con culturas distintas, sino un sistema de foros de deliberación intercultural auténticamente democrática. ${ }^{50}$

Lo anterior evidencia que el enfoque del nuevo constitucionalismo abarca el reconocimiento de las distintas culturas que coexisten en un mismo territorio, procurando garantizar los derechos de las mismas, en un enfoque de convivialidad, es decir, un

49. Agustín Grijalva, Constitucionalismo en Ecuador (Quito: Corte Constitucional para el Período de Transición, 2011), 92.

50. Ibíd., 93. 
reconocimiento, respeto y convivencia de calidad. Como corolario, Ávila ${ }^{51}$ sostiene que actualmente los sistemas jurídicos y las fuentes se diversifican: tomando como referencia que, entre otros aspectos, las comunidades indígenas tienen normas, procedimientos y soluciones a conflictos con carácter de sentencia, lo cual se traduce en que "el sistema formal no es el único derecho y la ley ha perdido la cualidad de ser la única fuente del derecho. Lo que vivimos, en términos jurídicos, es una pluralidad jurídica". ${ }^{2}$

\section{A MANERA DE CONCLUSIONES}

Es una realidad que el derecho constitucional ha evolucionado y se ha transformado de manera considerable, partiendo de una dogmática rígida clásica, que data de unos doscientos años y que se manejaba de manera cerrada en relación a temas que hoy día son realidades.

Es así que dogmáticamente se evidenció el surgimiento de nuevas tendencias, como el neoconstitucionalismo, para el caso de Europa, y el denominado, nuevo constitucionalismo latinoamericano, para el caso de la región latinoamericana, que presentan particulares características, que trascienden del plano local. Sin embargo, se determinó que el hecho de materializar una Constitución no necesariamente se traduce en un nuevo constitucionalismo, pues deben tomarse en consideración aspectos comunes que propenden a la construcción de espacios trasnacionales. Esto último es la mayor expresión del nuevo constitucionalismo en virtud de que cada día gana más espacio la idea de la universalización del derecho constitucional, basado en diversos aspectos expuestos en este trabajo, entre los que destacan:

La constitucionalización del ordenamiento jurídico, es decir, cada vez más las áreas del derecho son invadidas por el derecho constitucional, el cual formula dogmas y principios que moldean cualquier especialidad del derecho, como área del derecho programática de todas las demás, lo cual se traduce en que actualmente no se estudia ninguna parcela del derecho sin contar con un sustento constitucional, verbigracia, los principios constitucionales particulares de cada rama que cuentan con respaldo de las normas supremas de cada Estado.

Por otra parte, existe un reconocimiento de la ciudadanía universal, una institución que comienza a ganar fuerza en el plano internacional, en virtud de que sobre la sobe-

51. Ramiro Ávila, El neoconstitucionalismo transformador (Quito: Universidad Andina Simón Bolívar, Sede Ecuador, 2011), 123-4.

52. Ibíd., 124. 
ranía de cada Estado priman los derechos humanos y fundamentales de las personas, $\mathrm{y}$, en ese sentido, se enaltece la libre movilidad humana como un aspecto natural en la sociedad contemporánea, que implica entender que cada vez existen menos ciudadanos pertenecientes a un Estado determinado, sino que se habla de ciudadanos del mundo, ciudadanía cosmopolita o pos-ciudadanía, lo cual implica que el derecho constitucional se va abriendo a un enfoque más universal, y la progresiva desaparición de la condición de extranjero.

En el mismo sentido, se cuentan con mecanismos universales y regionales de protección de los derechos humanos, como figuras inherentes a cada individuo, que son reconocidas de manera universal, por tanto, se supera la concepción local de protección e derechos, para abrirse paso a una concepción de protección transnacional, para lo cual se han generado mecanismos como el control de convencionalidad que procura la armonización del derecho interno, frente al Derecho Internacional de los Derechos Humanos, este importante aporte jurisprudencial cada vez va moldeando los ordenamientos jurídicos de cada Estado, para ajustarse a una protección real de los derechos humanos.

Asimismo, surgen otras teorías que se inscriben en la nota o idea de universalidad, tales como la teoría de los derechos fundamentales, que cada vez gana más espacio y poco a poco va hacia un estándar dogmático, que permite a los jueces contar con una solidez al momento de dilucidar cualquier controversia presentada en relación a normas y principios, tarea que se materializa gracias al trabajo de los jueces constitucionales, quienes poseen un rol fundamental al ejecutar la tarea hermenéutica en sus decisiones, escindiendo entre intereses en los cuales se ven involucrados principios, reglas y derechos constitucionales.

Por último, se evidencia un fenómeno en la región andina de reconocer las diversas nacionalidades que coexisten, como manifestaciones de culturas que manejan su propio sistema jurídico, por tanto, se habla de Estados plurinacionales, en los cuales, a pesar de existir una fuerte influencia de un modelo eurocéntrico, en las últimas décadas se propicia la convivialidad de dichos sistemas, en la cual el límite es el respeto de los derechos humanos.

Los espacios trasnacionales son determinantes para erigir un verdadero nuevo constitucionalismo, ya que, actualmente, ningún país puede desarrollarse integralmente sin manejarse de conformidad con todos los aspectos que propician esta apertura supra nacional. Quedarse en un plano local limitaría el ejercicio de los derechos universalmente reconocidos y representa un retroceso en el ámbito dogmático constitucional, ya que las teorías más recientes enaltecen la idea de contar con ciertas unificaciones internacionales en materia de derecho, que trascienden las ideas clásicas positivistas e incluso naturalistas, para decantarse por una idea de derecho constitucional universal. 


\section{BIBLIOGRAFÍA}

Aguilar, Gonzalo. "Derechos fundamentales-derechos humanos. ¿Una distinción válida en el siglo XXI?”. Boletín Mexicano de Derecho Comparado, nueva serie, año XLIII, n. ${ }^{\circ} 127$ (2010): 15-71. https://bit.ly/2RAqxFW.

Aguilera, Rafael. "La ciudadanía ante la globalización: nuevos modelos de la ciudadanía posnacional y transcultural". Revista de Derecho UNED, n. 8 (2011): 1-48. https://doi. org/10.5944/rduned.8.2011.11043.

Aranda, José. "Espacios transnacionales y derechos humanos de las migrantes y los migrantes". En Migración, democracia y desarrollo: la experiencia mexiquense, coordinado por Norma Baca, Francisco Herrera y Rocío González, 21-2. Ciudad de México: Instituto Electoral del Estado de México, 2009. https://bit.ly/3cjyYgK.

Aldunate, Eduardo. “Aproximación conceptual y crítica al neoconstitucionalismo". Revista de Derecho (Valdivia) 23, n. ${ }^{\circ} 1$ (2010): 79-102. https://dx.doi.org/10.4067/S071809502010000100004.

Alexy, Robert. "La validez del derecho". En Concepto y validez del derecho. Barcelona: Gedisa, 1994.

- Teoría de los derechos fundamentales, 3. ${ }^{\text {a }}$ reimp. Traducido por Ernesto Garzón Valdés. Madrid, 2002.

Ávila, Ramiro. El neoconstitucionalismo transformador. Quito: Universidad Andina Simón Bolívar, Sede Ecuador. 2011. https://bit.ly/2RzkW2s.

Barroso, Luis. "El neoconstitucionalismo y la constitucionalización del derecho en Brasil (El triunfo tardío del derecho constitucional en Brasil)". Revista de Derecho de la Universidad de Montevideo, año 6, n. ${ }^{\circ} 12$ (2007): 25-50. https://bit.ly/3a8hfXW.

Brysk, Alison, y Gershon Shafir. People Out of Place: Globalization, Human Rights, and the Citizenship Gap. Nueva York: Routledge, 2004.

Carbonell, Miguel. Los derechos fundamentales en México. Ciudad de México: Universidad Nacional Autónoma de México / Comisión Nacional de los Derechos Humanos, 2004.

—. "Nuevos tiempos para el constitucionalismo". En Neoconstitucionalismo(s), editado por Miguel Carbonell. Madrid: Trotta, 2003.

Castañeda, Paula. "La constitucionalización del derecho en la sociedad capitalista". Derecho y realidad: Revista de la Facultad de Derecho y Ciencias Sociales UPTC 8, n. 16 (2010): 67-77. https://bit.ly/2VuEnuA.

Castilla, Karlos. "Control de convencionalidad interamericano una propuesta de orden ante diez años de incertidumbre". Revista IIDH, n. ${ }^{\circ} 64$ (2016): 87-126.

Comanducci, Paolo. "Formas de (neo)constitucionalismo: un análisis metateórico". Traducido por Miguel Carbonell. Revista Isonomía, n. 16 (2002): 89-112. https://bit.ly/2K3BaN0.

De Dienheim, Cuauhtémoc. Constitucionalismo universal: la internacionalización y estandarización de los Derechos Humanos. Buenos Aires: Ad-Hoc, 2009. 
Ecuador. Código Orgánico Integral Penal. Registro Oficial, Suplemento 180, 10 de febrero de 2014.

-. Constitución de la República del Ecuador. Registro Oficial 449, 20 de octubre de 2008.

Estévez, Ariadna. “¿Derechos humanos o ciudadanía universal? Aproximación al debate de derechos en la migración”. Revista Mexicana de Sociología 78, n. ${ }^{\circ} 1$ (2016): 61-87. https:// bit.ly/2VzB7OG.

Ferrajoli, Luigi. Derechos y garantías: la ley del más débil. Madrid: Trotta, 1999.

—. Derecho y razón, teoría del garantismo penal, 10. ${ }^{\text {a }}$ ed. Madrid: Trotta, 2011.

Fernández, Francisco. “Carlos Ayala Corao: del diálogo jurisprudencial al control de convencionalidad”. Anuario Iberoamericano de Justicia Constitucional, n. ${ }^{\circ} 17$ (2013): 671-7. https://bit.ly/3cnddN3.

Grijalva, Agustín. Constitucionalismo en Ecuador. Quito: Corte Constitucional para el Período de Transición, 2011. https://bit.ly/2XA28E4.

Gargarella, Roberto. "Lo 'viejo' del 'nuevo' constitucionalismo latinoamericano". En Memorias Encuentro SELA. Río de Janeiro: Universidad de Yale, 11-14 de junio de 2015. https:// bit.ly/3a4dTVW.

- "Sobre el nuevo constitucionalismo latinoamericano". Revista Uruguaya de Ciencia Política 27, n. ${ }^{\circ} 1$ (2018): 109-29. https://bit.ly/2RBaXcQ.

Guichot, Virginia. Reconstruir la ciudadanía. Madrid: Dykinson, 2011.

Martín, Juan. Estado universal. Ni muros, ni fronteras. Bubok Publishing S.L., 2018.

Midón, Mario. Control de convencionalidad. Buenos Aires: Astrea, 2016.

Mila, Frank, y Karla Yánez. "El constitucionalismo ambiental en Ecuador”. Actualidad Jurídica Ambiental, n. ${ }^{\circ} 97$ (enero 2020). https://bit.ly/3ewlLTI.

Neubaum, Betiana. "El diálogo interjurisdiccional entre la Corte Interamericana y la Corte Suprema de la Nación Argentina. El control de convencionalidad y la interpretación conforme". Revista Electrónica Cátedra Jean Monnet (Universidad de Buenos Aires, Facultad de Derecho) 4, n. 2 (2016): 1-209. https://bit.ly/2RDQPa4.

Pozzolo, Susana. “Apuntes sobre neoconstitucionalismo". En Enciclopedia de filosofía y teoría del derecho, I, coordinado por Jorge Fabra y Álvaro Núñez, 363-4. Ciudad de México: Universidad Nacional Autónoma de México / Instituto de Investigaciones Jurídicas, 2015. https://bit.ly/2yaDWNX.

Rosenfeld, Michel. "Rethinking constitutional ordering in an era of legal and ideological pluralism". International Journal of Constitutional Law 6, n. ${ }^{\circ}$ 3-4 (julio-octubre 2008): 415 55. https://doi.org/10.1093/icon/mon023.

Salazar, Mauricio. "Espacios transnacionales. Migración y globalización. Teoría de la educación". Revista electrónica teoría de la educación. Educación y cultura en la sociedad de la información (Universidad de Salamanca) 9, n. 2 (2008). https://bit.ly/2xtY2mk.

Salazar, Pedro. "El nuevo constitucionalismo latinoamericano (una perspectiva crítica)". En El constitucionalismo contemporáneo. Homenaje a Jorge Carpizo, coordinado por Luis González y Diego Valadés, 345-87. Ciudad de México: UNAM, 2013. https://bit.ly/3bb9Yb8. 
Uprimny, Rodrigo. "Las transformaciones constitucionales recientes en América Latina: tendencias y desafíos". En El derecho en América Latina: un mapa para el pensamiento jurídico en el siglo XXI, coordinado por César Rodríguez. Buenos Aires: Siglo XXI, 2011. https://bit.ly/3aduV3P.

Viciano, Roberto, y Rubén Martínez. “Aspectos generales del nuevo constitucionalismo latinoamericano. El nuevo constitucionalismo en América Latina”. En Memorias del encuentro internacional. El nuevo constitucionalismo: desafíos y retos para el siglo XXI. Quito: Corte Constitucional del Ecuador para el Período de Transición, 2010. https://bit. ly/3cfta $7 \mathrm{~V}$. 